\title{
STUDI LITERATUR TEKNOLOGI FITOREMEDIASI UNTUK PEMULIHAN EKOSISTEM LAUT TERKONTAMINASI LOGAM BERAT
}

\author{
Widya Nilandita ${ }^{1}$ \\ ${ }^{\text {IP }}$ rogram Studi Teknik Lingkungan, Universitas Islam Negeri Sunan Ampel, Jl. Jend. A. Yani 117 Surabaya \\ Email:Widya.nilandita@uinsby.ac.id
}

\begin{abstract}
ABSTRAK
Ekosistem laut disinyalir banyak terkontaminasi bahan pencemar baik organik maupun in organik. Pencemaran inorganik berupa logam berat berasal dari berbagai aktivitas seperti industri, kapal dan pelabuhan, tumpahan minyak, pengolahan limbah maupun kegiatan pertambangan. Letak geografis ekosistem estuari sangat berpeluang menjadi tempat penumpukan limbah yang berasal dari kegiatan sepanjang pantai dan kegiatan sebelah hulu. Keseimbangan ekologi lingkungan perairan pantai akan tetap terjaga apabila keberadan mangrove dipertahankan karena mangrove dapat berfungsi sebagai biofilter, agen pengikat dan perangkap polusi. Teknologi-teknologi konvensional ini dianggap tidak ekonomis dan berdampak negative bagi ekosistem perairan. Studi literatur ini membahas tentang penggunaan mangrove dan cara menghitung potensi tumbuhan mangrove untuk fitoremediasi ekosistem laut yang terkontaminasi logam berat. Mangrove mempunyai kemampuan dalam menyerap logam berat, sehingga bisa digunakan untuk proses fitoremediasi pada ekosistem laut terutama ekosistem astuari.
\end{abstract}

Kata kunci: Kontaminasi logam berat, Ekosistem Laut, Fitoremediasi, Mangrove

\section{PENDAHULUAN}

Ekosistem laut merupakan salah satu ekosistem alamiah akuatik yang paling besar di planet bumi ini. Luas area laut memang mencakup hampir $80 \%$ wilayah bumi. Ekosistem laut dibagi menjadi beberapa ekosistem yaitu: ekosistem laut dalam dan ekosistem laut dangkal. Ekosistem laut disinyalir banyak terkontaminasi bahan pencemar baik organik maupun in organik. Pencemaran inorganik berupa logam berat berasal dari berbagai aktivitas seperti industri, kapal dan pelabuhan, tumpahan minyak, pengolahan limbah maupun kegiatan pertambangan (Peters et al., 1999). Selain itu, aktivitas pertanian yang menggunakan insektisida dan pupuk secara berlebihan juga akan meningkatkan konsentrasi logam berat yang berhilir di daerah pesisir (Alloway,1994; Hasim dan Hughes, 2009). Konsentrasi logam berat yang tinggi akan menyebabkan kerusakan lingkungan dan meningkatkan daya toksisitas, persistan dan bioakumulasi logam itu sendiri (Lindsey et al., 2004).

Secara geografis ekosistem estuari sangat berpeluang menjadi tempat penumpukan limbah yang berasal dari kegiatan sepanjang pantai dan kegiatan sebelah hulu. Dampak pencemaran dibagian hulu yang dihubungkan oleh aliran sungai, dapat segera dirasakan dampaknya oleh ekosistem perairan payau dan ekosistem pantai yang berada dibagian hilir sungai tersebut. Keseimbangan ekologi lingkungan perairan pantai akan tetap terjaga apabila keberadan mangrove dipertahankan karena mangrove dapat berfungsi sebagai biofilter, agen pengikat dan perangkap polusi. Masukan sumber pencemar sangat banyak, mangrove memilki toleransi yang tingi terhadap logam berat (Mac Farlane dan Burchet, 2001; Gunarto, 2014). Mangrove juga merupakan tempat hidup berbagai jenis gastropoda, kepitng pemakan detritus, dan bivalvia pemakan plankton sehinga akan memperkuat fungsi mangrove sebagai biofilter alami. Berbagai jenis ikan baik yang bersifat herbivora, omnivore maupun karnivora hidup mencari makan di sekitar mangrove terutama pada waktu air pasang (Gunarto, 2014).

Limbah logam berat merupakan polutan yang berbahaya bagi makhluk hidup yang mengalami keterpaparan oleh unsur ini. Hal ini dikarenakan unsur logam berat merupakan unsur yang tidak dapat diciptakan maupun tidak dapat hancur (non degradable) sehinga selalu ada di alam. Selain itu unsur logam berat juga memilki kemampuan daya racun yang tingi dan dapat terakumulasi pada jaringan tubuh makhuk hidup sehinga keberadanya di lingkungan sangat tidak dinginkan (Kariada.N et al, 2014).

Proporsi utama penghilangan logam berat adalah melalui proses pengikatan (Kadlec dan Keoleian, 1986). Muatan positif logam berat menyebabkan logam berat dapat segera terserap, dikomplekskan dan diikat dengan partikel tersuspensi, yang kemudian menetap di substrat. Pengendapan logam berat sebagai garam tidak larut seperti karbonat, bikarbonat dan hidroksida dalam proses lain yang mengarah pada penghapusan logam berat jangka 
panjang. Garam-garam ini dibentuk oleh reaksi logam berat dengan bahan kimia lain yang hadir dalam kolom air dan tidak larut sehingga garam mengendap ke bawah menjadi tetap dalam substrat lahan basah (Sheoran dan Sheoran, 2006).

Endapan alkali, kolam pertukaran ion, penyerapan secara elektrokimia, teknologi membrane filtrasi adalah teknologi yang tersedia untuk menghilangkan logam berat. Teknologi-teknologi konvensional ini dianggap tidak ekonomis dan berdampak negative bagi ekosistem perairan.

Fitoremediasi adalah suatu teknologi pemanfaatn tumbuhan untuk mengurangi bahkan menghilangkan kehadiran bahan pencemar di dalam tanah dan air. Fitoremediasi menjadi pilihan menjajikan mengingat tidak membutuhkan biaya yang besar dan secara estetik mendukung upaya penghijauan lingkungan.

\section{EKOSISTEM LAUT}

Ekosistem air laut biasanya juga dinamakan sebagai ekosistem bahari. Ekosistem air laut merupakan ekosistem paling luas di permukaan bumi. Lebih dari dua pertiga bagian bumi ini merupakan ekosistem laut. Ekosistem air laut ditandai oleh salinitas (kadar garam) yang tinggi dengan ion Cl dapat mencapai 55\% terutama di daerah laut tropik, karena suhunya tinggi (sekitar $25^{\circ} \mathrm{C}$ ) dan penguapan besar. Pada daerah dingin, suhu air laut merata sehingga air dapat bercampur, hal ini mengakibatkan daerah permukaan laut tetap subur dan banyak plankton serta ikan. Gerakan air dari pantai ke tengah menyebabkan air bagian atas turun ke bawah dan sebaliknya, sehingga memungkinkan terbentuknya rantai makanan yang berlangsung baik.Ekosistem air laut juga dapat dibagi lagi menjadi ekosistem:

a. Ekosistem laut dalam

Ekosistem laut dalam terdapat di laut dalam atau palung laut yang gelap karena tidak dapat ditembus oleh cahaya matahari. Pada ekosistem laut dalam tidak ditemukan produsen. Organisme yang dominan, yaitu predator dan ikan yang pada penutup kulitnya mengandung fosfor sehingga dapat bercahaya di tempat yang gelap.

b. Ekosistem terumbu karang

Ekosistem terumbu karang terdapat di laut yang dangkal dengan air yang jernih. Organisme yang hidup di ekosistem ini, antara lain hewan terumbu karang (Coelenterata), hewan spons (Porifera), Mollusca (kerang, siput), bintang laut, ikan, dan ganggang. Ekosistem terumbu karang di Indonesia yang cukup terkenal di antaranya Taman Nasional Bawah Laut Bunaken.

c. Ekosistem estuari

Ekosistem estuari terdapat di daerah percampuran air laut dengan air sungai. Salinitas air di estuari lebih rendah daripada air laut, tetapi lebih tinggi daripada air tawar, yaitu sekitar $5-25 \mathrm{ppm}$. Di daerah estuari dapat ditemukan tipe ekosistem yang khas, yaitu padang lamun (seagrass) dan hutan mangrove.

- Padang lamun, merupakan habitat pantai yang biasanya ditumbuhi seagrass. Tumbuhan ini memiliki rizom dan serabut akar, batang, daun, bunga, bahkan ada yang berbuah. Seagrass berbeda dengan alga karena mempunyai sistem reproduksi dan pertumbuhan yang khas. Seagrass tumbuh menyebar membentuk padang rumput di dalam air dengan perpanjangan rizom. Jenis hewan di padang lamun, antara lain duyung (Dugong dugon), bulu babi(Tripneustes gratilla), kepiting renang (Portunus pelagicus), udang, dan penyu.

- Ekosistem hutan mangrove, terdapat di daerah tropis hingga subtropis. Ekosistem ini didominasi oleh tanaman bakau (Rhizophora sp.), kayu api (Avicennia sp.), dan bogem (Bruguiera sp.). Tumbuhan bakau memiliki akar yang kuat dan rapat untuk bertahan di lingkungan berlumpur yang mudah goyah oleh hempasan air laut. Akar napasnya berfungsi untuk mengambil oksigen langsung dari udara. Tumbuhan bakau memiliki buah dengan biji vivipari yang sudah berkecambah dan berakar panjang saat masih di dalam buah sehingga langsung tumbuh ketika jatuh ke lumpur. Hewan-hewan yang hidup di ekosistem ini, antara lain burung, buaya, ikan, biawak, kerang, siput, kepiting, dan udang. Hutan mangrove banyak terdapat di pesisir pulau Sumatra, Jawa, Kalimantan, Papua, Bali, dan Sumbawa.

d. Ekosistem pantai pasir

- Ekosistem pantai pasir terdiri atas hamparan pasir yang selalu terkena deburan ombak air laut. Di tempat ini angin bertiup kencang dan cahaya matahari bersinar kuat pada siang hari. Vegetasi atau tumbuhan yang dominan adalah formasi pes-caprae dan formasi barringtonia. Formasi pes-caprae terdiri atas tanaman berbatang lunak dan berbiji (terna), misalnya Ipomoea pes-caprae, Vigna marina, dan Spinifex littoreus. Formasi barringtonia terdiri atas perdu dan pohon, misalnya Barringtonia asiatica, Terminalia catappa, Erythrina, Hibiscus tiliaceus, dan Hernandia. 
Hewan yang hidup di pantai pasir, misalnya kepiting dan burung. Pantai pasir antara lain terdapat di

Bali, Lombok, Papua, Bengkulu, dan Bantul (Yogyakarta).

e. Ekosistem pantai batu Sesuai dengan namanya, ekosistem Sesuai dengan namanya, ekosistem pantai batu memiliki banyak bongkahan batu besar maupun batu kecil. Organisme dominan di smi, yaitu ganggang cokelat, ganggang merah, siput, kerang, kepiting, dan burung. Ekosistem ini banyak terdapat di pantai selatan Jawa, pantai barat Sumatra, Bali, Nusa Tenggara dan Maluku.

\section{TEKNOLOGI FITOREMEDIASI LOGAM BERAT EKOSISTEM LAUT}

Terkait dengan fitoremidiasi di pesisir, perlu diketahui karakteristik fisikokimia perairan dan sedimen (Yoon et al., 2006). Kondisi fisikokimia perairan akan berpengaruh terhadap kondisi sedimen dan fisiologi serta pertumbuhan mangrove. Di sedimen, kandungan logam berat yang ada juga sangat dipengaruhi oleh kapasitas pertukaran ion, $\mathrm{pH}$, redoks, spesiasi logam berat, ketersedian nutrien dan salinitas sedimen (Greger, 2004). Fitoremidiasi dihitung dengan tiga pendekatan biologi yaitu:

1. Biological Accumulation Coefficient (BAC) (Khan et al., 2013). BAC juga sama dengan Enrichment Coefficient (EF) dimana didapatkan dengan cara membagi konsentrasi logam pada sedimen konsentrasi logam berat dengan daun (Cui et al., 2007)

$\mathrm{BAC} / \mathrm{EF}=[$ Logam Berat $]$ Daun/[Logam Berat $]$ Sedimen

2. Biological Transfer Coefficient (BTC) atau Translocation Factor (TF) didefinisikan sebagai konsentrasi logam berat pada daun dibagi dengan konsentrasi logam berat pada akar (Zu et al., 2005; Cui et al., 2007; MacFarlane et al., 2007; Khan et al., 2013).

$\mathrm{BTC} / \mathrm{EF}=[$ Logam Berat $]$ daun/[Logam Berat $]$ akar

3. Bio-Concentration Factor (BCF) adalah rasio antara konsentrasi logam berat pada akar dengan konsentrasi logam berat pada sedimen (Yoon et al., 2006; MacFarlane et al., 2007; Khan et al., 2013).

$\mathrm{BCF}=[$ Logam Berat $]$ akar/[Logam Berat $]$ sediment

Sebuah penelitian yang dilakukan oleh Hamzah (2013), di Hutan Lindung Muara Angke Kapuk dan Taman Margasatwa Muara Angke, menunjukkan bahwa organ akar dan daun tumbuhan Rhizophora mucronata, Rhizopora apiculata, Sonneratia caseolaris dan Avicennia marina memiliki kemampuan menyerap logam berat $\mathrm{Pb}, \mathrm{Cu}$ dan $\mathrm{Zn}$ (Tabel 1)

Tabel 1. Kandungan logam Cu, Zn, dan PB pada Akar dan Daun

\begin{tabular}{|c|c|c|c|c|c|c|c|c|c|c|c|c|}
\hline \multirow[b]{2}{*}{ No } & \multirow[b]{2}{*}{ Parameter } & \multirow[b]{2}{*}{ Setuan } & \multicolumn{10}{|c|}{ Lokasi danSpesies mangrove } \\
\hline & & & $\begin{array}{c}\text { B- } \\
\text { RA } 1\end{array}$ & $\begin{array}{c}\text { A- } \\
\text { RA } 2\end{array}$ & $\begin{array}{c}\text { A- } \\
\text { RA } 3\end{array}$ & $\begin{array}{c}\text { B- } \\
\text { RM } 1\end{array}$ & $\begin{array}{c}\mathrm{A} \\
\mathrm{RM} 2\end{array}$ & $\begin{array}{c}\text { B- } \\
\text { AM } 1\end{array}$ & $\begin{array}{c}\mathrm{A} \\
\mathrm{AM} 2\end{array}$ & $\stackrel{\mathrm{C}-}{\mathrm{SC} 1}$ & $\underset{\mathrm{SC} 2}{\mathrm{C}}$ & $\begin{array}{c}\text { D. } \\
\mathrm{SC} 3\end{array}$ \\
\hline & \multicolumn{12}{|l|}{ Akar } \\
\hline 1 & $\mathrm{Cu}$ & ppm & 6,12 & 11,49 & 9,69 & 10,38 & 7,6 & 11,95 & 10,39 & 7,32 & 9,95 & 8,92 \\
\hline 2 & $Z_{n}$ & ppm & 40,42 & 50,54 & 39,27 & 40,08 & 68,35 & 45,01 & 43,96 & 49,57 & 53,22 & 55,93 \\
\hline 3 & $\mathrm{~Pb}$ & ppm & 51,32 & 54,92 & 55,62 & 53,28 & 55,27 & 50,89 & 50,71 & 50,16 & 52,22 & 54,72 \\
\hline \multicolumn{13}{|c|}{ Daun } \\
\hline 1 & $\mathrm{Cu}$ & ppm & 3,83 & 5,67 & 1,16 & 1,73 & 2,43 & 4,68 & 6,93 & 2,14 & 3,18 & 7,34 \\
\hline 2 & $Z_{n}$ & ppin & 38,94 & 39,88 & 35,65 & 35,73 & 38,24 & 48,98 & 48,86 & 47,16 & 46,59 & 55,5 \\
\hline 3 & $\mathrm{~Pb}$ & ppm & 49,41 & 51,89 & 58,45 & 49,23 & 46,57 & 58,57 & 53,42 & 48,75 & 48,09 & 50,38 \\
\hline
\end{tabular}

Kr'bek dk (201) dalam penelitanya menyampaikan, bahwa mangrove merupakan hyperacumulators yang baik, mangrove bukan saja mampu tumbuh di tanah dengan konsentrasi unsur beracun yang tingi, tetapi mereka juga mengumpulkan/ mengakumulasi unsur tersebut di dalam batang dan daun dengan jumlah yang mungkin lebih tingi dan mematikan bagi organisme hidup lainya. Beberapa tanaman (metalophytes) dapat tumbuh dalam substrat dengan kondisi konsentrasi logam yang sangat tinggi (salt dk, 195; broks 198; boyd 207 dalam kr'bek dk, 201). Clark dk (198) dalam kumar dk (201), ekosistem mangrove memainkan peran penting sebagai filter dan pengendalian polusi alami karena kekhasan system akarnya yang berhasil mengendalikan kualitas air dan merupakan perangkap sedimen serta partikel yang diangkut oleh arus ke lautan dari muara. 
Hamzah dkk (2013) juga meneliti besar konsentrasi logam berat seberapa besar konsentrasi kandungan logam berat dari lingkungan yang diserap oleh jaringan akar, kemudian disebar dan diakumulasikan kejaringan lainnya (daun dan kulit batang) dengan menghitung BAC, BCF dan BTC (tabel 2)

Tabel 2. Nilai BCF daun, BCF akar dan TF mangrove

\begin{tabular}{lcccccccccc}
\hline \multirow{2}{*}{ Spesies } & \multirow{2}{*}{ Stasiun } & \multicolumn{3}{c}{ BAC daun } & \multicolumn{4}{c}{ BCF akar } & \multicolumn{3}{c}{ BTC } \\
\cline { 3 - 11 } & & $\mathrm{Cu}$ & $\mathrm{Zn}$ & $\mathrm{Pb}$ & $\mathrm{Cu}$ & $\mathrm{Zn}$ & $\mathrm{Pb}$ & $\mathrm{Cu}$ & $\mathrm{Zn}$ & $\mathrm{Pb}$ \\
\hline Rhizophora mucronata 1 & $\mathrm{B}$ & 0,02 & 0,13 & 0,90 & 0,15 & 0,15 & 0,97 & 0,17 & 0,89 & 0,92 \\
Rhizophora mucronata 2 & $\mathrm{A}$ & 0,03 & 0,13 & 0,84 & 0,11 & 0,22 & 0,99 & 0,32 & 0,56 & 0,84 \\
Rhizophora apiculata 1 & $\mathrm{B}$ & 0,06 & 0,14 & 0,90 & 0,09 & 0,14 & 0,93 & 0,63 & 0,96 & 0,96 \\
Rhizophora apiculata 2 & $\mathrm{A}$ & 0,08 & 0,13 & 0,93 & 0,16 & 0,17 & 0,99 & 0,49 & 0,79 & 0,94 \\
Rhizophora apiculata 3 & $\mathrm{A}$ & 0,02 & 0,12 & 1,05 & 0,13 & 0,13 & 1,00 & 0,12 & 0,91 & 1,05 \\
Sonneratia caseolaris 1 & $\mathrm{C}$ & 0,04 & 0,21 & 1,06 & 0,17 & 0,16 & 0,93 & 0,29 & 0,95 & 0,97 \\
Sonneratia caseolaris 2 & $\mathrm{C}$ & 0,05 & 0,21 & 1,05 & 0,14 & 0,14 & 0,91 & 0,32 & 0,88 & 0,92 \\
Sonneratia caseolaris 3 & $\mathrm{D}$ & 0,13 & 0,25 & 1,10 & 0,13 & 0,25 & 1,09 & 0,82 & 0,99 & 0,92 \\
Avicennia marina 1 & $\mathrm{B}$ & 0,07 & 0,17 & 1,07 & 0,15 & 0,14 & 0,97 & 0,39 & 1,09 & 1,15 \\
Avicennia marina 2 & $\mathrm{A}$ & 0,10 & 0,16 & 0,96 & 0,11 & 0,22 & 0,99 & 0,67 & 1,11 & 1,05 \\
\hline
\end{tabular}

MacFarlane et al. (2007); dan Khan et al. (2013) menyatakan bahwa untuk mengetahui seberapa besar perpindahan logam dari satu jaringan ke jaringan yang lain, bisa diketahui dari faktor bioakumulasi/enrichment (BAC/EC), biokonsentrasi (bioconcentration factor/BCF) dan biotranslokasi (BTC/TF). Dalam hal ini, BAC/EC merupakan rasio kandungan logam berat dalam daun dengan kandungan logam berat pada sedimen, BCF merupakan rasio kandungan logam berat dalam akar dengan kandungan logam berat di sedimen, sedangkan BTC/TF merupakan rasio konsentrasi logam berat dalam daun dan akar. Selain itu, BCF dan BTC bisa digunakan untuk mengetahui potensi tumbuhan untuk tujuan fitoremidiasi (Yoon et al., 2006).

Untuk tujuan fitoremidiasi, Hamzah dkk (2013) melakukan pendekatan BAC, BCF dan BTC dengan kriteria spesies tumbuhan yang memiliki nilai BAC dan BCF tinggi, namun nilai BTC-nya rendah (Yoon et al.,2006). Untuk mempermudah perhitungan fitoremidiasi dilakukan pengurangan antara nilai BAC/BCF dengan BTC dan hasilnya adalah FTD daun dan akar (Tabel 3)

Tabel 3 Nilai FTD daun dan akar mangrove

\begin{tabular}{cccccccc}
\hline Spesies & \multirow{2}{*}{ Stasiun } & \multicolumn{3}{c}{ FTD Daun } & \multicolumn{3}{c}{ FTD Aks } \\
\cline { 3 - 8 } & & $\mathrm{Cu}$ & $\mathrm{Zn}$ & $\mathrm{Pb}$ & $\mathrm{Cu}$ & $\mathrm{Zn}$ & $\mathrm{Pb}$ \\
\hline Rhizophoramucronata 1 & $\mathrm{B}$ & $-0,14$ & $-0,77$ & $-0,03$ & $-0,02$ & $-0,74$ & $-0,77$ \\
Rhizophoramucronata 2 & $\mathrm{A}$ & $-0,29$ & $-0,43$ & $-0,01$ & $-0,21$ & $-0,33$ & 0,15 \\
Rhizophoraapiculata 1 & $\mathrm{B}$ & $-0,57$ & $-0,83$ & $-0,06$ & $-0,54$ & $-0,82$ & $-0,03$ \\
Rhizophoraapiculata 2 & $\mathrm{A}$ & $-0,42$ & $-0,66$ & $-0,01$ & $-0,33$ & $-0,62$ & 0,04 \\
Rhizophoraapiculata 3 & $\mathrm{A}$ & $-0,10$ & $-0,79$ & 0,00 & $-0,01$ & $-0,78$ & $-0,05$ \\
Sonneratiacaseolaris 1 & $\mathrm{C}$ & $-0,26$ & $-0,74$ & 0,09 & $-0,12$ & $-0,79$ & $-0,05$ \\
Sonneratiacaseolaris 2 & $\mathrm{C}$ & $-0,27$ & $-0,67$ & 0,13 & $-0,18$ & $-0,73$ & $-0,01$ \\
Sonneratiacaseolaris 3 & D & $-0,70$ & $-0,75$ & 0,18 & $-0,70$ & $-0,77$ & 0,17 \\
Avicennia manina 1 & $\mathrm{B}$ & $-0,32$ & $-0,92$ & $-0,08$ & $-0,24$ & $-0,95$ & $-0,18$ \\
Avicennia manina 2 & A & $-0,57$ & $-0,95$ & $-0,09$ & $-0,56$ & $-0,89$ & $-0,06$ \\
\hline
\end{tabular}

Berdasarkan hasil perhitungan FTD akar dan daun dapat disimpulkan bahwa Sonneratia caseolaris 3 diduga dapat digunakan untuk tujuan fitoremidiasi khususnya fitostabilisasi. Penelitian Nazli,dkk (2010) juga berkesimpulan bahwa Sonneratia caseolaris potensial untuk digunakan dalam fitoremediasi. Proses akumulasi dan mobilisasi logam dengan menggunakan jaringan akar dikenal dengan istilah fitostabilisasi. Fitostabilisasi mampu meminimalisir pergerakan polutan (logam berat) dalam sedimen (Susarla et al., 2002).

\section{KESIMPULAN}


Mangrove memiliki kemampuan menyerap logam berat dari lingkungan, sehingga bisa digunakan sebagai agen fitoremediasi pada ekosistem laut terutama ekosistem estuari. Diperlukan penelitian untuk menggali potensi tumbuhan mangrove lainnya yang biasa digunakan dalam proses fitoremediasi.

\section{DAFTAR PUSTAKA}

Alloway, B.J. 1994. Toxic Metals in Soil-Plant Systems, Chichester, Uk: John Wiley and Sons.

Gunarto. 2014. Konservasi Mangrove Sebagai Pendukung Sumberhayati Perikanan Pantai. Jurnal Litbang Pertanian 23 (1): 15-21.

Cui, S., Q. Zhou \& L. Chao. 2007. Potential Hyperaccumulator of Pb, Zn, Cu and Cd in Endurant Plants Distributed in an Old Smeltery, Northeast China. Environ. Geol. 51:1043-1048.

Hamzah, F. \& Pancawati,Y. 2013. Fitoremidiasi Logam Berat dengan Menggunakan Mangrove. Ilmu Kelautan. Vol. 18(4):203-212

Hashim, N.R. \& F. Hughes. 2009. The Responses of Secondary Forest tree Seedlings to Soil enrichment in Peninsular Malaysia: An Experimental Approach. Trop. Ecol. 3(1):50-55.

Kadlec, P.H \& Keoleian,G.A. 1986. Metal Ion Exchange on Peat. In Peat and water, PP 61-93 (Fuchsman, C. H., Ed) Amsterdam Elsevier.

Khan, M.U., M. Ahmed, S.S. Shaukat, K. Nazim \& Q.M. Ali. 2013. Effect of Industrial Waste on Early Growth and Phytoremidation Potential. Avicennia Marina (Forsk.) Vierh. Pak. J. Bot, 45(1):17-27.

Kr'bek, B., Mihaljevic, M., Sracek, O., Kne'sl, I., Etler, V. dan Nyambe, I. 201. The Extent of Arsenic and of Metal Uptake by Aboveground Tisues of Pteris vitata and Cyperus involucratus Growing in Coper- and Cobalt- Rich Tailngs of the Zambian Coperbelt. Arch Environ Contam Toxicol 61:28-242.

MacFarlane, G.R. \& M.D. Burchett. 2001. Photosynthetic Pigments and Peroxides Activity as Indicators of Heavy Metal Stress in the Grey Mangrove Avicennia marina (Forsk.) Veirh. Mar. Poll. Bull. 42: 233-240.

MacFarlane, G.R., C.E. Koller \& S.P. Blomberg. 2007. Accumulation and Partitioning of Heavy Metals in Mangroves: A Synthesis of Field Based Studies. Chemosphere. 69:1454-1464.

Nazli, M.F \& Hashim, N.R. 2010. Heavy metal concentration in an Important Mangrove Species, Sonneratia caseolaris,in Peninsular Malaysia. EnvironmentAsia 3(special issue) (2010) 50-55. on line www.tshe.org/EA. (Akses tanggal 1 Agustus 2015).

Peters, E.C., N.J. Gassman, J.C. Firman, R.H. Richmond \& E.A. Power. 1997. Ecotoxicology of Tropical Marine Ecosystems. Environ. Toxicol. Chem. 16:12-40.

Sheoran, A.S \& Sheoran, V. 2006. Heavy metal removal mechanism of acid mine drainage in wet land: a critical review. Mineral Eng, 19:105-116

Susarla, S., V.F. Medina \& S.C. McCutcheon. 2002. Phytoremediation, an Ecological Solution to Organic Contamination. Ecol. Eng. 18:647-658.

Yoon, J., C. Xinde, Z. Qixing \& L.Q. Ma. 2006. Accumulation of Pb, Cu, and $\mathrm{Zn}$ in Native Plants Growing on a Contaminated Florida Site. Sci. Total Environ. 368(2-3):456-464.

Zu, Y.Q., Y. Li, J.J. Chen, H.Y. Chen, L. Qin \& C. Schvartz. 2005. Hyperaccumulation of Pb, Zn and Cd in herbaceous grown on lead-zinc mining area in Yunnan, China. Environ. Internat. 31:755-762. 